\title{
Exploring the Learning Styles and Study Strategies used by Brunei High Mathematics Achievers
}

\author{
Halimaturradiah Metussin \\ Sultan Hassanal Bolkiah Institute of Education, Jalan Tungku Link, Gadong BE1410 \\ Bandar Seri Begawan, Brunei Darussalam; Email: hal_412@hotmail.com
}

\section{Doi:10.5901/mjss.2016.v7n1p435}

\section{Abstract}

\begin{abstract}
The gender disparity in Brunei school leaver mathematics examination results is a source of concern for parents, teachers and the education system. The present survey $(N=315)$ compared the learning styles and study strategies of Brunei Year 13 (preuniversity/foundation) students. The common practices of top math achievers (both genders) included using active reading, adequate preparations before tests, thinking deeply, and employing memory techniques. Overall, high math achievers were stronger in study strategies rather than learning styles compared to the average and low achievers. Females were dominant in the high achieving group while males outnumbered females among the low achievers. To improve weak students' performance in mathematics, workshops that show students how to effectively engage in reading, concentration, note-taking, memorisation techniques, deep processing, and time management should be undertaken. In addition, students with high support needs should be encouraged to attend motivational talks, small group discussions, remedial classes, or one-to-one sessions with their mathematics teachers, counsellors, and educational psychologists. Further mixed-methods research was recommended to gain additional insights and solutions.
\end{abstract}

Keywords: Gender gap; tertiary institutions; learning styles; study strategies; mathematics achievement.

\section{Introduction and Background}

Enrolment records in Brunei high education institutions show that there are more female than male students. The difference in the numbers of males and females accepted in Brunei tertiary institutions cannot be attributed to differences in the birth rates of boys versus girls (Department of Statistics (2011a). The most recent statistics on the Brunei population indicate no significant difference among genders by age group (Department of Statistics (2011b), while data from hospital records and population census statistics reveal that an almost equal number of children of both genders are born each year (Department of Statistics (2011a). The gender gap is also not explained by the natural infant mortality rate, according to hospital statistics for the death rate (Department of Statistics (2011b). In addition, Brunei society does not practice gender-related infanticide and parents of every ethnicity care for all their children irrespective of gender, disability, or race. Furthermore, school registration rates show that a nearly equal number of boys and girls enter school each year, and are retained in the education system until they complete their General Certificate of Education (GCE) Ordinary (0) Levels (Year 11) (Department of Planning, Development and Research, 2010). Only a few children (mostly boys) repeat one year during their schooling due to a variety of reasons, including illness, disability or poor performance.

At the GCE O Level, both personal counselling and educational interventions are provided to students with special needs through the Ministry of Education's relevant organisational structures (the Special Education Unit and Guidance and Counselling Unit). As a result, there seems to be an even number of students of both genders progressing from Year 1 right up to GCE O-Level. However, the transition from O Level to Advanced Subsidiary (AS) Level (Year 12) leading to Advanced (A) Level (Year 13) is keenly contested and only a small number of girls and boys enter the few available Sixth-Form Colleges that serve as a pre-university foundation stage.

The gender gap seems to arise during the GCE AS and A Levels (Years 12 to 13). It is at this stage that it is apparent that females begin to far outperform their male counterparts in key subjects, such as mathematics and English, which are frequently included among the admission criteria of colleges and universities in Brunei. This has resulted in fewer males than females being admitted to colleges and universities. Mathematics, in particular, is a subject which challenges Brunei students at all levels of education (Mundia, 2010a). 


\subsection{Factors impacting teaching and learning in Brunei}

In general, low performance in any subject including mathematics may be due to a number of reasons such as the poor quality of teaching, inadequate or inappropriate learning resources, and low interest or motivation in the subject. Brunei has already made major attempts to improve the quality of education in the country. For example, the curriculum was recently reformed (Mundia, 2010a). In 2009, teacher education was also innovated in order to improve the quality of teaching (Mundia, 2012a). Prospective teachers undergo a rigorous interview to ensure that they are mentally sound (Mundia, 2013). Efforts are also currently being made to prepare teachers who have high self-efficacy in special education (Bradshaw \& Mundia, 2005; Bradshaw \& Mundia, 2006; Haq \& Mundia, 2012; Tait \& Mundia, 2012a; Tait \& Mundia, 2013). Like other students elsewhere in the world, Brunei students also have both personal and academic problems which impact learning and achievement adversely. Most of these factors, such as disability, behavioural disorders, depression, anxiety and stress are psychological and require counselling interventions to address them at school and at home (Mundia, 2006; Mundia, 2010b; Tait \& Mundia, 2012b). In addition, differences in career preferences might also lead students to develop varying levels of interest and motivation for studying subjects (Mundia, 1998).

\subsection{Mathematics anxiety, self-esteem and test stress versus academic achievement}

Besides learning styles and study strategies, there are many other factors that affect achievement in mathematics. However, only the roles of mathematics anxiety, self-esteem, and test stress are briefly reviewed here. Mathematics anxiety has been found to have a number of negative effects on the learners such as indulging in procrastination, having interpretational anxiety, harbouring test and class anxiety, developing a negative computational self-concept, and fostering a fear of the mathematics or statistics instructor (Onwuegbuzie, 2001). Previous research shows that mathematics anxiety correlates negatively with mathematics performance or achievement (Daneshamooz and Alamolhodaei, 2012).

Self-esteem is another variable which is believed to affect academic achievement positively or negatively. Baumeister et al. (2003) found that there was only a modest correlation between self-esteem and school performance. This suggested that high self-esteem in itself does not necessarily lead to good performance. Instead, high self-esteem might partly be the result of good school performance. Stress is the other factor that has negative effects on academic achievement. According to Malik and Balda (2006) academic achievement was negatively correlated with all types of stress assessed in this study. Ford (1993), Moore (1997) and Alatorre and Reyer (1999) also found such negative relationship between academic achievement and psychological stress.

\subsection{Objectives of the study}

Causes of the disparity in mathematics achievement between female and male students in Sixth Form Colleges are difficult to understand given that the two genders were comparable on many levels. For instance, both grew up in the same country, went to government schools, and were taught mostly by Brunei nationals trained within the country. The present study was one of the three investigations conducted by the same author(s) that sought to identify potential factors that facilitate or inhibit math achievement in males at GCE O-Level. Of the many suspected causal factors, the present study compared the scores of low and high achieving math female and male students on learning styles and study strategies variables. The importance of learning styles and study strategies in learning mathematics was emphasised by earlier research (Mundia, 2007; Mundia, 2012b). Briefly, the three main objectives of the present study were to:

1. Determine the differences in learning styles and study strategies between the female and male students.

2. Examine the differences in learning styles and study strategies variables between the low, average and high achievers in mathematics.

3. Investigate the differences in mathematics ability and achievement by gender

The rationale and justification for including these research objectives and variables in the study was three-fold. First, due to lack of research, the degree to which these variables impact performance in mathematics is not known in the Brunei context. Second, if these variables could help improve achievement in mathematics examinations for males, then equating gender performance at "O" Level examinations in mathematics might be the key to partly addressing and reducing the gender gap in tertiary student populations. Third, pre-university students in Brunei undergo two stressful years of preparing for "AS" and "A" Level examinations. It might be helpful to know if effective management of personality factors was related to good academic performance in mathematics. 


\section{Method}

Sections 2.1- 2.5 below briefly explain how the present study was conducted.

\subsection{Design}

The field survey procedure was employed to research the problem. Under this strategy, the researcher personally went to Sixth Form Colleges to collect the data. This type of design was thus different from other forms of surveys (e.g. postal, telephone, online, and longitudinal). The rationale and justification for employing this design is that it enabled the researcher to collect the required data within a short time.

\subsection{Sample}

Two random samples were used in this study. The pilot study had 32 participants ( 16 females, Mean age $=20.125, S D=$ 1.586 and 16 males, Mean age $=21.375, \mathrm{SD}=2.802$ ). Participants in the pilot sample came from one Sixth Form Centre (also known as Pre-University College in Brunei). Data collected from this trial sample were not included in the main study. The main study sample consisted of 330 participants who were chosen using the simple random selecting technique. Of these, 179 were females (Mean age $=17.543, S D=0.061$ ) and 151 were males (Mean age $=17.799, S D=$ 0.805). Participants in the main study came from six different Sixth Form Centres. There were two inclusion criteria. First, both genders were recruited. Second, all participants were drawn from GCE A-Level (Year 13) cohorts.

\subsection{Instruments}

One of the major problems facing educational researchers in Brunei is getting suitable research instruments. The majority of the existing instruments are written in advanced English and often too long (e.g. see Mundia, 2011). In addition only few instruments have been translated to Bahasa Melayu, the official language of Brunei spoken by the majority (Mundia, 2010c). The data for the present study were collected by two quantitative psychometric tests and one educational test), namely: the College Level Study Skills Inventory Scale, CLSSI (Congos, 2011); the Learning Styles Questionnaire, LSQ (Honey \& Mumford, 1986; 1992); and an adopted Scholastic Aptitude Test (SAT) mathematics test, 40 items (Diehl \& Joyce, 2006). All these were written in simple English and did not need to be translated to Bahasa Melayu.

The CLSSI (Congos, 2011) is a 51-item questionnaire divided into the following 6 subscales: Text book reading (8 items); Note-taking (5 items); Memory (9 items); Test preparation (13 items); Concentration (10 items); and Time management (6 items). Each item is rated on a 5-point Likert-type scale ranging from $1=$ Almost never, through $3=$ About half of the time, to $5=$ Almost always.

The short version Learning Styles Questionnaire, LSQ (Honey \& Mumford, 1986; 1992) is a 40-item scale divided into four thematic subscales measuring the following types of learners: Activist (10 items), Reflector (10), Theorist (10), and Pragmatist (10). Each item has two response options, and is scored as either a "tick" (1) or a "cross" (0). Total subscale scores range from 0-10 (median $=5.5$ ). Subscale scale scores below 4 and above 7 are regarded as low and high respectively.

The 40-item objective SAT mathematics test (Diehl \& Joyce, 2006) covered eight topics (algebra, plane geometry, solid geometry, coordinate geometry, trigonometry, functions, probability and statistics, and numbers and operations) which are taught to all students in Brunei secondary schools up to GCE O-Level. Each item had four-response options (A, $B, C, D, E)$ with one correct answer and three distractors scored dichotomously as zero (0) if wrong and as one (1) when right. Altogether the 40 items measured a wide range of high-order skills such as understanding, interpretation, synthesis, application, evaluation, and critical thinking. The difficulty for this test was set at the GCE O-Level standard. SAT tests are international college selection / entrance assessments. They are taken by students all over the world with Year 11 and above level of education. In terms of contents, the test was suitable for Brunei students in Years 12-13.

Clarifications made to the participants on completing each instrument correctly helped to increase the number of usable returns. Using data from the trial sample, the quality, suitability and feasibility of the instruments were determined. The scale descriptive statistics and reliability are presented in Table 1 while validity indices for the measures are provided in Table 2. The instruments were both reliable and valid for use with Brunei Year 13 students. 
Table 1: Descriptive statistics, standard Error of measurement and alpha reliability

\begin{tabular}{|c|c|c|c|c|c|c|c|c|}
\hline Scale Name & Subscale & Number of Items & Maximum Score $^{1}$ & Mean & $\mathrm{SD}^{2}$ & SEmeas $^{3}$ & Average I-S Correlation 4 & Alpha Reliability \\
\hline \multirow{8}{*}{ CLSSI } & Textbook Reading & 8 & 40 & 24.089 & 4.580 & 2.713 & 0.344 & 0.649 \\
\hline & Note-taking & 5 & 25 & 15.396 & 4.135 & 2.219 & 0.474 & 0.712 \\
\hline & Memory & 9 & 45 & 29.946 & 6.284 & 2.914 & 0.473 & 0.785 \\
\hline & Test Preparation & 13 & 65 & 38.912 & 6.887 & 3.512 & 0.367 & 0.740 \\
\hline & Concentration & 10 & 50 & 36.224 & 5.212 & 3.110 & 0.329 & 0.644 \\
\hline & Time Management & 6 & 30 & 14.884 & 4.981 & 2.445 & 0.501 & 0.759 \\
\hline & Deep Processing & 5 & 25 & 15.412 & 3.173 & 2.054 & 0.364 & 0.581 \\
\hline & Surface Processing & 5 & 25 & 19.182 & 3.924 & 1.555 & 0.651 & 0.843 \\
\hline \multirow{4}{*}{ LSQ } & Activist & 10 & 10 & 5.220 & 2.173 & 1.402 & 0.262 & 0.584 \\
\hline & Reflector & 10 & 10 & 7.751 & 1.833 & 1.239 & 0.242 & 0.543 \\
\hline & Theorist & 10 & 10 & 7.533 & 1.692 & 1.256 & 0.180 & 0.449 \\
\hline & Pragmatist & 10 & 10 & 7.560 & 1.577 & 1.277 & 0.130 & 0.344 \\
\hline SAT & Math & 40 & 40 & 27.218 & 7.824 & 2.437 & 0.417 & 0.903 \\
\hline
\end{tabular}

Table 2: Convergence validity and discriminant validity by inter-scale correlations

\begin{tabular}{|c|c|c|c|c|c|c|c|c|c|c|c|}
\hline Scale Name & Subscale & Mean & $\mathrm{SD}^{1}$ & 1 & 2 & 3 & 4 & 5 & 6 & 7 & 8 \\
\hline \multirow{8}{*}{ CLSSI } & Textbook Reading & 23.355 & 5.695 & 1 & & & & & & & \\
\hline & Note-taking & 15.091 & 4.548 & $0.507^{* *}$ & 1 & & & & & & \\
\hline & Memory & 29.088 & 7.557 & $0.656^{\star *}$ & $0.623^{* *}$ & 1 & & & & & \\
\hline & Test Preparation & 37.764 & 9.077 & $0.628^{* *}$ & $0.636^{\star *}$ & $0.628^{* *}$ & 1 & & & & \\
\hline & Concentration & 35.188 & 7.616 & $0.551^{\star *}$ & $0.523^{* *}$ & $0.652^{* *}$ & $0.674^{\star *}$ & 1 & & & \\
\hline & Time Management & 14.500 & 5.368 & $0.512^{\star *}$ & $0.529 * *$ & $0.512^{\star *}$ & $0.589^{* *}$ & $0.486^{* *}$ & 1 & & \\
\hline & Deep Processing & 14.900 & 4.125 & $0.546^{* *}$ & $0.373^{* *}$ & $0.580^{* *}$ & $0.634^{\star \star}$ & $0.607^{* *}$ & $0.384^{* *}$ & 1 & \\
\hline & Surface Processing & 18.636 & 4.981 & $0.432^{\star \star}$ & $0.381^{* *}$ & $0.497^{\star \star}$ & $0.561^{\star \star}$ & $0.646^{* *}$ & $0.354^{\star *}$ & $0.436^{\star \star}$ & 1 \\
\hline SAT & Math & 23.712 & 9.879 & $0.225^{\text {tk }}$ & $0.122^{*}$ & $0.197^{\text {t* }}$ & $0.191^{* *}$ & $0.167^{\text {tk }}$ & -0.038 & $0.168^{* k}$ & 0.052 \\
\hline \multirow{5}{*}{ LSQ } & Subscale & Mean & $\mathrm{SD}^{1}$ & 1 & 2 & 3 & 4 & 5 & 6 & 7 & 8 \\
\hline & Activist & 4.994 & 2.360 & 1 & & & & & & & \\
\hline & Reflector & 7.349 & 2.358 & 0.051 & 1 & & & & & & \\
\hline & Theorist & 7.173 & 2.242 & $0.200^{\star *}$ & $0.641^{* *}$ & 1 & & & & & \\
\hline & Pragmatist & 7.179 & 2.176 & $0.449 * *$ & $0.521^{* *}$ & 0.579 ** & 1 & & & & \\
\hline SAT & Math & 23.712 & 9.879 & $-0.175^{\text {*t }}$ & $0.158^{* *}$ & $0.124^{*}$ & 0.000 & & & & \\
\hline
\end{tabular}

${ }^{1}$ Standard deviation of total scores

* $p<0.05$ (two-tailed)

** $p<0.01$ (two-tailed)

\subsection{Procedures}

This study was originally done as part of the PhD doctoral dissertation research using sponsorship funds from the University of Brunei Darussalam. Permission to collect the data from the Sixth Form Centres (schools) was obtained from the Ethical Committee of the University. In addition, permission to conduct the study in schools was also granted by the Ministry of Education in the Government of Brunei Darussalam. Ethical requirements for involvement in the study were explained to all the participants in groups. These included anonymity, confidentiality, voluntary participation as well as physical and psychological harm. No deception was used. Only students who voluntarily agreed to participate in the study were recruited as respondents. The researcher had no conflict of interest.

\subsection{Data analysis}

The two psychometric scales and the SAT test of mathematics were scored according to instructions in their respective technical manuals. Raw quantitative data were analysed by a variety of procedures that included descriptive statistics, 
correlation, t-test for independent groups, and One-Way ANOVA.

\section{Results}

The results of the study are presented below according to the data collection instruments used.

\subsection{Findings from the Learning Styles Questionnaire}

Table 3 indicates that low math achievers were more active learners than average and top math scorers $(p<0.01)$. No significant differences were obtained on other learning styles variables listed in the table.

Table 3: Participants' performance on the learning styles inventory by ability in Mathematics $(N=315)$

\begin{tabular}{|c|c|c|c|c|c|c|c|c|c|}
\hline \multirow[t]{2}{*}{ Subscale } & \multicolumn{2}{|c|}{$\begin{array}{l}\text { Bottom } \\
(n=85)\end{array}$} & \multicolumn{2}{|c|}{$\begin{array}{c}\text { Middle } \\
(n=142)\end{array}$} & \multicolumn{2}{|c|}{$\begin{array}{c}\text { Top } \\
(n=88)\end{array}$} & \multirow{2}{*}{$\begin{array}{c}F \\
(d f=2,314)\end{array}$} & \multirow{2}{*}{$\begin{array}{c}P \\
\text { (2-tailed) }\end{array}$} & \multirow[t]{2}{*}{ Eta } \\
\hline & Mean & SD & Mean & SD & Mean & SD & & & \\
\hline Activist & 5.659 & 2.423 & 5.085 & 2.277 & 4.511 & 2.062 & 5.572 & $0.004^{\star *}$ & 0.186 \\
\hline Reflector & 6.988 & 2.408 & 7.711 & 2.051 & 7.557 & 2.143 & 3.021 & 0.050 & 0.138 \\
\hline Theorist & 6.988 & 2.398 & 7.366 & 2.026 & 7.398 & 1.992 & 1.053 & 0.350 & 0.082 \\
\hline Pragmatist & 7.247 & 2.143 & 7.542 & 1.801 & 6.966 & 2.184 & 2.281 & 0.104 & 0.120 \\
\hline
\end{tabular}

In terms of gender, females were more reflective $(p<0.05)$ and theoretical $(p<0.01)$ learners than their male counterparts, as indicated in Table 4.

Table 4: Participants' performance on the learning styles scale by gender $(\mathrm{N}=315)$

\begin{tabular}{|c|c|c|c|c|c|c|c|c|}
\hline \multirow[t]{2}{*}{ Subscale/Scale } & \multicolumn{2}{|c|}{$\begin{array}{l}\text { Females } \\
(n=174)\end{array}$} & \multicolumn{2}{|c|}{ Males $(n=141)$} & \multirow{2}{*}{$\begin{array}{c}\text { ANCOVA } \\
\mathrm{F} \dagger\end{array}$} & \multirow{2}{*}{$\begin{array}{c}\mathrm{T} \\
(\mathrm{df}=313)\end{array}$} & \multirow{2}{*}{$\begin{array}{c}P \\
\text { (2-tailed) }\end{array}$} & \multirow[t]{2}{*}{ Effect Size } \\
\hline & Mean & SD & Mean & SD & & & & \\
\hline Activist & 4.856 & 2.142 & 5.355 & 2.447 & $1.415 \mathrm{~ns}$ & 1.926 & 0.055 & 0.085 \\
\hline Reflector & 7.724 & 2.080 & 7.163 & 2.292 & $0.171 \mathrm{~ns}$ & -2.274 & $0.024^{*}$ & 0.126 \\
\hline Theorist & 7.552 & 1.964 & 6.929 & 2.267 & $0.723 \mathrm{~ns}$ & -2.611 & 0.009 ** & 0.131 \\
\hline Pragmatist & 7.420 & 1.744 & 7.156 & 2.306 & $3.361 \mathrm{~ns}$ & -1.154 & 0.249 & 0.076 \\
\hline
\end{tabular}

\subsection{Findings from the College Level Study Skills Inventory}

According to Table 5 and Tukey HSD, top math achievers significantly higher than average and low math achievers because they read textbooks ( $<0.01)$, memorize to remember what they learn $(p<0.05)$, and prepare well before the tests $(p<0.05)$. Moreover, high math achievers also use deep processing or understanding when learning and studying $(p<0.05)$. In terms of concentration skills, average and top math scorers concentrate the most when learning and studying, compared to low math scorers $(p<0.05)$.

Table 5: Participants' performance on the College Level Study Skills Inventory by ability in mathematics $(N=315)$

\begin{tabular}{|c|c|c|c|c|c|c|c|c|c|}
\hline \multirow[t]{2}{*}{ Subscale } & \multicolumn{2}{|c|}{$\begin{array}{l}\text { Bottom } \\
(n=85)\end{array}$} & \multicolumn{2}{|c|}{$\begin{array}{c}\text { Middle } \\
(n=142)\end{array}$} & \multicolumn{2}{|c|}{$\begin{array}{c}\text { Top } \\
(\mathrm{n}=88)\end{array}$} & \multirow{2}{*}{$\begin{array}{c}F \\
(d f=2,314)\end{array}$} & \multirow{2}{*}{$\begin{array}{c}\mathrm{P} \\
\text { (2-tailed) }\end{array}$} & \multirow[t]{2}{*}{ Eta } \\
\hline & Mean & $\mathrm{SD}^{1}$ & Mean & $\mathrm{SD}^{1}$ & Mean & $\mathrm{SD}^{1}$ & & & \\
\hline Textbook Reading & 22.165 & 6.334 & 23.732 & 4.620 & 24.818 & 4.765 & 5.754 & $0.004^{\star \star}$ & 0.189 \\
\hline Note-taking & 14.435 & 4.463 & 15.599 & 4.405 & 15.511 & 3.916 & 2.164 & 0.117 & 0.117 \\
\hline Memory & 27.847 & 8.469 & 29.472 & 6.188 & 30.943 & 6.126 & 4.404 & $0.013^{*}$ & 0.166 \\
\hline Test Preparation & 36.329 & 9.802 & 38.423 & 7.347 & 39.909 & 6.805 & 4.431 & $0.013^{*}$ & 0.166 \\
\hline Concentration & 34.141 & 8.809 & 36.401 & 5.867 & 36.193 & 4.722 & 3.486 & $0.032^{*}$ & 0.148 \\
\hline
\end{tabular}




\begin{tabular}{|c|c|c|c|c|c|c|c|c|c|}
\hline Time Management & 14.824 & 5.604 & 15.254 & 5.120 & 13.580 & 4.697 & 2.929 & 0.055 & 0.136 \\
\hline Deep Processing & 14.506 & 4.556 & 14.852 & 3.415 & 16.000 & 3.126 & 4.045 & $0.018^{*}$ & 0.159 \\
\hline Surface Processing & 18.424 & 5.186 & 19.387 & 4.146 & 18.727 & 4.198 & 1.382 & 0.253 & 0.094 \\
\hline
\end{tabular}

Evidence in Table 6 suggested that females effectively use all of the study skills variables to perform better in math than males (except in deep processing). Females do more reading $(p<0.05)$, note-taking $(p<0.01)$ and memorizing techniques $(p<0.01)$ compared to their male counterparts who use deep processing when learning and studying $(p<$ 0.05). Furthermore, females concentrate $(p<0.01)$ and manage their learning and studying time better $(p<0.01)$ than males while using surface processing the most $(p<0.01)$.

Table 6: Participants' performance on the College Level Study Skills Inventory by Gender ( $N=315)$

\begin{tabular}{|c|c|c|c|c|c|c|c|c|}
\hline \multirow[t]{2}{*}{ Subscale/Scale } & \multicolumn{2}{|c|}{$\begin{array}{l}\text { Females } \\
(n=174)\end{array}$} & \multicolumn{2}{|c|}{$\begin{array}{c}\text { Males } \\
(n=141)\end{array}$} & \multirow{2}{*}{$\begin{array}{c}\text { ANCOVA } \\
\mathrm{F}\end{array}$} & \multirow{2}{*}{$\begin{array}{c}\mathrm{T} \\
(\mathrm{df}=313)\end{array}$} & \multirow{2}{*}{$\begin{array}{c}P \\
\text { (2-tailed) }\end{array}$} & \multirow[t]{2}{*}{ Effect Size } \\
\hline & Mean & $\mathrm{SD}^{1}$ & Mean & $\mathrm{SD}^{1}$ & & & & \\
\hline Textbook Reading & 24.144 & 5.181 & 22.957 & 5.285 & 0.322 & 2.003 & $0.046^{*}$ & 0.134 \\
\hline Note-taking & 16.397 & 3.763 & 13.858 & 4.529 & 2.855 & 5.433 & 0.000 ** & 0.302 \\
\hline Memory & 30.471 & 6.785 & 28.177 & 6.934 & 0.010 & 2.955 & $0.003^{* *}$ & 0.171 \\
\hline Test Preparation & 39.017 & 7.485 & 37.355 & 8.603 & 0.366 & 1.833 & 0.068 & 0.134 \\
\hline Concentration & 36.713 & 5.445 & 34.525 & 7.610 & 9.103 & 2.969 & $0.003^{\star \star}$ & 0.176 \\
\hline Time Management & 15.638 & 5.095 & 13.475 & 5.039 & 0.225 & 3.765 & $0.000^{\star *}$ & 0.214 \\
\hline Deep Processing & 14.695 & 3.500 & 15.553 & 3.938 & 0.844 & -2.045 & $0.042^{*}$ & 0.073 \\
\hline Surface Processing & 19.713 & 3.906 & 17.993 & 4.929 & 3.674 & 3.455 & $0.001^{\star \star}$ & 0.192 \\
\hline
\end{tabular}

${ }^{1}$ Standard deviation of total scores

${ }^{*} p<0.05$ (2-tailed)

${ }^{* *} p<0.01$ (2-tailed)

\subsection{Findings from the SAT mathematics test}

According to Table 7, there is a significant difference between females and males in mathematics ability. Females scored significantly higher in math than their male peers $(p<0.01)$.

Table 7: Participants' performance on the mathematics test by gender $(N=315)$

\begin{tabular}{|c|c|c|c|c|c|c|c|c|}
\hline \multirow[t]{2}{*}{ Scale } & \multicolumn{2}{|c|}{$\begin{array}{l}\text { Females } \\
(n=174)\end{array}$} & \multicolumn{2}{|c|}{$\begin{array}{c}\text { Males } \\
(n=141)\end{array}$} & \multirow{2}{*}{$\begin{array}{c}\text { ANCOVA } \\
\mathrm{F} \dagger\end{array}$} & \multirow{2}{*}{$\begin{array}{c}T \\
(\mathrm{df}=313)\end{array}$} & \multirow{2}{*}{$\begin{array}{c}P \\
\text { (2-tailed) }\end{array}$} & \multirow[t]{2}{*}{ Effect Size } \\
\hline & Mean & $\mathrm{SD}^{1}$ & Mean & $\mathrm{SD}^{1}$ & & & & \\
\hline Mathematics & 26.178 & 7.197 & 23.192 & 9.863 & $26.902 \mathrm{~ns}$ & 3.103 & $0.002^{\star \star}$ & 0.173 \\
\hline
\end{tabular}

\section{Discussion}

The results of the present study are discussed according to the three objectives of the research stated above.

\subsection{Differences in learning styles and study strategies between the female and male students}

- According to this study, females were more reflective $(p<0.05)$ and theoretical $(p<0.01)$ learners than their male counterparts as indicated in Table 4

- In addition, evidence in Table 6 indicated that females effectively used all of the study strategies to perform better in math than males (except in deep processing). For example, females do more reading $(p<0.05)$, note-taking $(p<0.01)$ and memorizing techniques $(p<0.01)$ compared to their male counterparts who use 
deep processing when learning and studying $(p<0.05)$. Furthermore, females concentrate $(p<0.01)$ and manage their learning and studying time better $(p<0.01)$ than males. They also use surface processing more effectively than males $(p<0.01)$.

\subsection{Differences in using learning styles and study strategies between the low and high achievers in mathematics}

- As shown in Table 3, low math achievers were more active learners than top math scorers $(p<0.01)$.

- In terms of Table 5 and Tukey HSD, top math achievers performed significantly higher than average and low math achievers because they read textbooks $(p<0.01)$, memorize to remember what they learn $(p<0.05)$, and prepare well before the tests $(p<0.05)$. Moreover, high math achievers also use deep processing or understanding when learning and studying $(p<0.05)$. In addition, top math scorers concentrate the most when learning and studying compared to low math scorers $(p<0.05)$.

\subsection{Differences in ability and achievement on a mathematics test}

- According to evidence in Table 7, there was a significant difference in mathematics ability between females and males. Females scored significantly higher in math than their male peers $(p<0.01)$.

According to the findings from the present study, the common practices of top math achievers included reading, preparing adequately before tests, thinking deeply, and using remembering or memory effectively. These characteristics are summarised in Table 8 and were the skills that need to be taught to low math achievers. As can be observed from this table, high math achievers were stronger in study strategies rather than learning styles (compared to the average and low achievers). In addition, females were predominant in the high achieving group while males outnumbered females among the low achievers.

Table 8: Characteristics of the participants by ability in mathematics

\begin{tabular}{|c|c|c|}
\hline $\begin{array}{c}\text { Top Scorers } \\
(F=\underline{50}, M=38)\end{array}$ & $\begin{array}{l}\text { Average Scorers } \\
(F=\underline{93}, M=49)\end{array}$ & $\begin{array}{c}\text { Low Scorers } \\
(F=31, M=\underline{54})\end{array}$ \\
\hline $\begin{array}{cl}\text { Study Strategies } \\
\text { - } & \text { read textbook }(p<0.01) \\
\text { - } & \text { memory }(p<0.05) \\
\text { - } & \text { preparation }(p<0.05) \\
\text { - } & \text { teep processing }(p<0.05) \\
\text { - } & \text { surface processing }(p<.01)\end{array}$ & $\begin{array}{l}\text { Study Strategies } \\
\quad \quad \text { Concentration }(p<0.05)\end{array}$ & $\begin{array}{l}\text { Learning Styles } \\
\quad \quad \text { Active learners }(p<0.01)\end{array}$ \\
\hline
\end{tabular}

Learning styles refer to a student's reasonably consistent response to and use of stimuli in an educational context. It is the combination of the behaviour that they engage in when learning and is not necessarily a fixed or static construct (Stapleton, 2001). On other hand, study strategies (also known as learning strategies) are described as a collection of mental tactics employed by an individual in a particular learning situation to facilitate acquisition of knowledge or skill (Derry \& Murphy, 1986).

To improve male students' performance in mathematics, workshops should that encourage and show them how to engage more effective reading, note-taking, memorisation techniques and deep processing when learning mathematics, should be undertaken. Moreover, they should also be taught how to concentrate and manage their time in the most effective and efficient manner. It is important to enforce these workshops to ensure that male mathematics students are not left behind.

Students who have little interest in studying mathematics should attend motivational talks, small group discussions or one-on-one sessions with their mathematics teachers, counsellors and educational psychologists so that these students can express their concerns regarding mathematics, and learn the importance of mathematics as a subject and as a skill that is needed in everyday life. During these discussions, students should be exposed to many different ways of studying mathematics as an initiative to develop their interest in the subject. In addition, they should be encouraged to change their idea of mathematics as being a difficult and challenging subject, and be encouraged to enjoy mathematics. 


\section{Conclusion}

Evidence from the present study suggested that study strategies contribute more to effective learning of mathematics than learning styles. The research identified a number of study strategies that high achievers in mathematics, who were mostly females, used. Low achievers in mathematics, who were mainly males, appeared to be more dependent on the use of the active learning style. Workshops on effective use of study strategies were recommended to help males to perform better in mathematics. Further mixed-methods research was desired to gain additional insights and solutions to the problem.

\section{Limitations}

There were two main limitations to this research. First, the variables investigated were only limited to learning styles and study strategies. Inclusion of other factors such as home environment, teaching effectiveness, school quality, the nature of the curriculum, assessment procedures and language difficulties might have expanded the findings but this was going to require more time, resources and practical considerations to implement. Moreover, each of these factors is very broad and embraces a wide range of issues. Second, as a survey the findings of the study could not actually show cause-andeffect relationships among the variables investigated. Despite these limitations, the study had practical significance in that it addressed one of the major problems in the Brunei tertiary education system.

\section{References}

Alatorre A. S., \& Reyes, R. L. (1999). Psychological stress, internalized symptoms and academic achievement of Hispanic adolescents. Journal of Adolescent Research, 14, 343-358. http://dx.doi.org/10.1177/0743558499143004

Baumeister, R. F., Campbell, J. D., Krueger, J. I., \& Vohs, K. D. (2003). Does high self-esteem cause better performance, interpersonal success, happiness, or healthier lifestyles? Psychological Science in the Public Interest, 4(1), 1-44. http://dx.doi.org/10.1111/ 1529-1006.01431

Bradshaw, L., \& Mundia, L. (2005). Understanding preservice teachers' construct of disability: a metacognitive process. Disability and Society, 20 (5): 563-574.

Bradshaw, L., \& Mundia, L. (2006). Attitudes to and concerns about inclusive education: Bruneian inservice and preservice teachers. International Journal of Special Education, 21 (1), 35-41.

Congos, D. H. (2011). College Level Study Skills Inventory. Orlando, FL: University of Central Florida.

Daneshamooz, S., \& Alamolhodaei, H. (2012). Cooperative learning and academic hardiness on students' mathematical performance with different levels of mathematics anxiety. Educational Research, 3(3), 270-276.

Department of Planning, Development and Research. (2010). Education Statistics Brunei Darussalam. Brunei Darussalam: Ministry of Education.

Department of Statistics. (2011a). Brunei Darussalam Key Indicators. Bandar Seri Begawan: Department of Economic Planning and Development, Prime Ministers' Office.

Department of Statistics. (2011b). Brunei Darussalam Statistical Yearbook 2011. Bandar Seri

Begawan: Department of Economic Planning and Development, Prime Ministers' Office.

Derry, S. J. \& Murphy, D. A. (1986). Designing systems that train learning ability: From theory to practice. Review of Educational Research, 56, 1-39.

Diehl, J. J., \& Joyce, C. E. (2006). Math Level 1 and Level 2 - 15 practice SAT subject tests. New York, NY: McGraw-Hill.

Ford, D. Y. (1993). An investigation of paradox of under achievement among gifted black students. Roeper Review, 16(2), 78- 84. http://dx.doi.org/10.1080/02783199309553544

Haq, F. S., Mundia, L. (2012). Comparison of Brunei pre-service student teachers' attitudes to inclusive education and specific disabilities: Implications for teacher education. Journal of Educational Research, 105 (5), 366-374.

Honey, P., \& Mumford, A. (1986). Using your learning styles. Maidenhead: Honey.

Honey, P., \& Mumford, A. (1992). The manual of learning styles. Maidenhead: Honey.

Malik, P. R., \& Balda, S. (2006). High IQ adolescents under stress: Do they perform, Poorly? Anthropologist, 8(2), 61-62.

Moore, B. J. (1997). Three case studies of gifted students who underachieve in high school. Dissertation Abstracts International Section A: Humanities and Social Sciences, 57(6-A), 3394.

Mundia, L. (1998). The status of technical subjects in Papua New Guinea provincial high schools: A survey of attitudes. Science, Technology and Development. 16 (2): 104-111.

Mundia, L. (2006). Aggressive behaviour among Swazi upper primary and junior secondary school students: implications for ongoing educational reforms concerning inclusive education. International Journal of Special Education, 21 (3), 58-67.

Mundia, L. (2007). Early childhood education in Swaziland and Brunei Darussalam: goals, achievements and challenges. Early Child Development and Care, 177 (2), 151-158.

Mundia, L. (2010a). Problems in learning mathematics: Comparison of Brunei junior high school students in classes with and without 
repeaters. Journal of Mathematics Research, 2 (3), 150-160.

Mundia, L. (2010b). Prevalence of depression, anxiety and stress in Brunei student teachers. Internet Journal of Mental Health, 6(2). Available online at: http://www.ispub.com/journal/the_internet_journal_of_mental_health.html

Mundia, L. (2010c). Implementation of SPN21 curriculum in Brunei Darussalam: A review of selected implications on school assessment reforms. International Education Studies, 3 (2), 119-129.

Mundia, L. (2011). Social desirability, non-response bias and reliability in a long self-report measure: Illustrations from the MMPI-2 administered to Brunei student teachers. Educational Psychology, 31 (2), 207-224.

Mundia, L. (2012a). Policy changes in Brunei teacher education: Implications for the selection of trainee teachers. The Education Forum, 76 (3), 326-342.

Mundia, L. (2012b). The Assessment of Mathematics Learning Difficulties in a Primary Grade 4 Child with High Support Needs: Mixed Methods Approach. International Electronic Journal of Elementary Education. 4 (2), 347-366.

Mundia, L., \& Bakar, HAZBA. (2010). The suitability of the EPQ-R short scale for counseling Brunei student teachers when administered in English and Malay languages. Compare, 40 (5), 641-658.

Mundia, L. (2013). Relationship Between Mental Health and Teaching: Evidence from Brunei Trainee Teachers. International Journal of Mental Health, 42 (2/3), 73-98. DOI: 10.2753/IMH0020-7411420205.

Onwuegbuzie, A. J. (2001). I will begin my statistics assignment tomorrow: The relationship, between statistics anxiety and academic procrastination. Retrieved May 21, 2015, from http://www.fearofstatisticscourse.htm

Stapleton, M. (2001). Psychology in practice: education. London: Hodder Education.

Tait, K., \& Mundia, L. (2012a). Preparing teachers to meet the challenges of inclusive education in Negara Brunei Darussalam. In C. I. Forlin (Ed.), Future directions for inclusive teacher education: An international perspective (pp. 60-69). Hong Kong: Routledge/Francis \& Taylor.

Tait, K. \& Mundia, L. (2012b). The impact of a child with autism on the Bruneian family system. International Journal of Special Education, 27 (3), 1-14.

Tait, K., \& Mundia, L (2013). A Comparison of Brunei and Hong Kong - SAR Student Teachers' Self-efficacy in Implementing Inclusive Education Practices: Implications for Teacher Education. Asian Social Science. 10 (1), 51-60. DOI:10.5539/ass.v10n1p51 